\title{
ASPECTS OF THE POLLTNATION ECOLOGY OF SELECTED NATIVE FLORA IN GRAND TETON NATIONAL PARK
}

\author{
Ron L. Scogin \\ Rancho Santa Ana Botanic Garden \\ Claremont, California
}

\section{Objectives}

My investigations during July and August, 1984 at the U.W.-N.P.S. Research Center had two primary objectives, both involving problems of pollination ecology of flora native to Grand Teton National Park:

1. A survey of the distribution of floral coloration on a community basis within the park; and

2. A preliminary study of the pollination ecology of the color morphs of Delphinium occidentale (Ranunculaceae).

\section{STUDIES OF FLORAL AND VEGEATTIVE COLORATION}

The object of this study is to examine the relationships among flowering phenology, principal pollinators, and floral coloration. The goal is to quantitatively represent floral color and floral/vegetative color contrast as perceived by the visiting pollinator and to test the hypothesis that flowering times within plant communities have evolved so as to maximize the visual contrast among flowers blooming at any given time and hence minimize interspecific competition for pollinator services.

One data set necessary for this investigation is a precise measure of flower color in the form of a reflectance spectrum from flower material over both the visible (to humans) and ultraviolet (visible to insects) wavelength ranges. During my work at the Research Center I determined the UV-visible reflectance spectra for 68 native plant species from communities ranging from alpine meadow to the valley floor. Included among these were taxa which exhibit color polymorphism and for which spectral data for both morphs were determined (e.g., Ipomopsis aggregata, Campanula rotundifolia, Penstemon whippleanus, and Delphinium occidentale). These reflectance spectra are now being digitalized for numerical analysis and colorimetric representation of flower color. These data will then be combined with flowering schedule data to examine patterns of flower color dispersion through the blooming season within communities.

\section{POLLTNATION ECOLOGY OF DELPHINIUM OCCIDENTALE}

It was noted that populations of Delphinium occidentale (the duncecap larkspur) within the national park are polymorphic with respect to flower pigmentation. Three morphs exist in mixed populations: a dark-purple form; an entirely white, 
albino form; and a "semi-albino" form, in which the outer portion of the corolla lobes in albino, but the central portion of the flower is pigmented normally. The frequencies at which these morphs occur is far too high to be due to spontaneous mutation. They must, therefore, be maintained by some form of selective pressure which almost certainly revolves around their pollination ecology. To determine what the selective factors might be which maintain these forms in natural populations, various aspects of the morphs were compared.

1. The approximate relative frequencies of the three morphs were noted and suggested that around one-third of all inflorescences were partially or totally albino; far too many to be maintained by spontaneous mutation.

2. The standing nectar crop was about 1 microliter per spur ( 2 microliters per flower) and had a sugar concentration of $35 \%$ in sucrose equivalents. This provides an energy source of about 1.5 calories per spur. The differences in nectar chemistry among morphs was not significant at the level of the preliminary sampling performed.

3. Pollen samples of the three morphs are indistinguishable by microscopic examination.

4. The anthocyanin pigment present in pigmented corolla is delphinidin 3, 5-diglucoside. An additional pigment is present in trace amounts and has not yet been completely characterized.

5. Seed set in pigmented, open pollinated flowers is $10-16$ seeds per follicle. Seed set for albino flowers was not determined. A seed predation rate by an unidentified insect larva of about $1 \%$ was noted.

6. Nectar sugar composition is sucrose dominated and not significantly different among the three morphs. There are additional, unusual nectar sugar constituents in all morphs which have not yet been completely characterized.

7. A high frequency of nectar robbery occurs, as well as legitimate pollination visitation. Representatives of both classes of visitors were captured and preserved and will be sent to experts for identification. Both are bumblebee species.

8. Reflectance spectra of floral parts of all three morphs were determined and are presently being analyzed in terms of differences in color appearance to bumblebee pollinators.

Preliminary data suggest that floral polymorphism in this taxon is being maintained by pollinator behavioral patterns in response to some aspect of the floral biology of the morphs. Clarification of the mechanism of morph maintainence will require collection of more extensive field data and performance of controlled crossing experiments.

\section{ADDITIONAL RESEARCH PERFORMED}

As part of an ongoing research program examining the reproductive phytochemistry of the genus Penstemon, floral pigments and nectar samples were collected from P. attenuatus, P. whippleanus, P. cyananthus, P. montanus, and $\underline{P}$. deustus. Analysis of these materials is complete and those results are being incorporated into two manuscripts in preparation. 